\title{
Rendimento de pimentão em função da adubação orgânica e mineral
}

\author{
Maria Aparecida N Sediyama ${ }^{1 ; 2}$; Sanzio M Vidigali; ${ }^{1 ; 2}$ Marlei Rosa dos Santos ${ }^{1}$; Luís Tarcísio Salgado ${ }^{1}$ \\ ${ }^{1}$ EPAMIG-CTZM, C. postal 216, 36570-000 Viçosa-MG; ${ }^{2}$ Bolsista BIPDT/FAPEMIG; marians@epamig.ufv.br
}

\begin{abstract}
RESUMO
O experimento foi conduzido a campo na Fazenda Experimental da EPAMIG, em Oratórios (MG), com o objetivo de avaliar o efeito da adubação orgânica associada à adubação mineral na produção de pimentão. O delineamento experimental foi de blocos casualizados, com quatro repetições, no esquema fatorial $4 \times 3$, quatro doses de adubo orgânico $\left(0 ; 30 ; 60\right.$ e $\left.90 \mathrm{t} \mathrm{ha}^{-1}\right)$ e três de adubo mineral $(0$; 750 e $1500 \mathrm{~kg} \mathrm{ha}^{-1}$ da fórmula NPK 4-14-8 aplicados nos sulcos de plantio). Em cada parcela de $14 \mathrm{~m}^{2}$ foram distribuídas 28 mudas de pimentão, cultivar Magda, no espaçamento de 1,0 x 0,5 m. Avaliouse o teor de nutrientes nas folhas no início da floração, produção de frutos total, comercial e não comercial, os frutos comerciais foram classificados, com base no comprimento e diâmetro, em extra, especial e primeira. A classe extra foi responsável pela maior parte da produção de frutos comerciais. A adubação com composto orgânico foi eficiente na nutrição das plantas com incremento na produtividade de pimentão. A adubação mineral teve efeito aditivo na produção de frutos. A produtividade máxima de frutos comerciais foi estimada quando se associou 84,43 tha $\mathrm{t}^{-1}$ de composto orgânico com a maior dose de adubo mineral.
\end{abstract}

Palavras-chave: Capsicum annuum, nutrição, composto orgânico, dejeto de suínos.

\begin{abstract}
Yield of pepper depending on the organic and mineral fertilization

This experiment was carried out in a field in Oratorios, Minas Gerais State, Brazil, to evaluate the effect of organic fertilization associated to mineral fertilization on the production of pepper. The experiment was arranged in the randomized block design, with four replications, in a $4 \times 3$ factorial scheme; four doses of organic fertilizer $\left(0 ; 30 ; 60\right.$ and $\left.90 \mathrm{tha}^{-1}\right)$ three doses of mineral fertilization (0; 750 and $1500 \mathrm{~kg} \mathrm{ha}^{-1}$ of the NPK 4-14-8 formulation applied to furrows at planting). Twenty-eight pepper seedlings, cultivar Magda, were distributed into each $14 \mathrm{~m}^{2}$ plot, at $1.0 \times 0.5 \mathrm{~m}$ spacing. Nutrient contents were evaluated in the leaves at the beginning of flowering, production of total, commercial and non-commercial fruits were determined. Commercial fruits were classified based on the length and diameter, into extra, special and first class. The extra class accounted for most of the commercial fruit production. Fertilization with organic compost was efficient for pepper nutrition, increasing pepper yield. The mineral fertilizer had additional effect for fruit production. The highest yield of commercial fruits was estimated when associated $84.43 \mathrm{t} \mathrm{ha}^{-1}$ of composed organic with the highest dose of mineral fertilizer.
\end{abstract}

Keywords: Capsicum annuum, nutrition, organic compost, swine waste.

\section{(Recebido para publição em 30 de maio de 2008; aceito em 17 de agosto de 2009)} (Received in May 30 2008; accepted in August 17, 2009)

$\mathrm{O}^{\mathrm{p}}$ pimentão (Capsicum annuum L.) é uma das dez hortaliças de maior importância econômica no mercado brasileiro. A planta é bastante exigente quanto à fertilidade do solo e, como os solos brasileiros apresentam, em geral, baixa fertilidade faz-se uso de abubações orgânica e mineral, para torná-los compatíveis com as exigências da cultura. Resultados de pesquisas têm mostrado a importância da utilização de doses elevadas de adubos orgânicos e minerais para atender à demanda de nutrientes na cultura do pimentão (Melo et al., 2000; Ribeiro et al., 2000; Oliveira et al., 2004). Entretanto, a aplicação de adubos e corretivos é uma prática agrícola onerosa que representa, em média, $23,4 \%$ do custo de produção do pimentão (Ribeiro et al., 2000). Desta forma, estudos da interação entre fertilização não-convencional, ou seja, fertilizantes orgânicos alternativos em combinação com adubos minerais podem eliminar desperdícios e evitar efeitos fitotóxicos pois doses muito alta desequilibram as relações entre nutrientes e salinizam o solo (Rodrigues \& Casali, 1999).

A utilização de adubos orgânicos de origem animal torna-se prática útil e também econômica para os pequenos e médios produtores de hortaliças, proporcionando melhoria na fertilidade e na conservação do solo (Galvão et al., 1999). Esta prática, quando utilizada por vários anos consecutivos proporciona acúmulo de nitrogênio orgânico no solo, aumentando seu potencial de mineralização e sua disponibilidade para as plantas (Scherer, 1998). Segundo Filgueira (2000) as hortaliças reagem bem a este tipo de adubação, tanto em produtividade como em qualidade dos produtos obtidos, mas não está definido que os diferentes materiais orgânicos podem substituir parte da adubação mineral na cultura do pimentão (Roe et al., 1997).

Existe forte associação entre absorção de nutrientes e desenvolvimento da planta, sendo a produtividade extremamente dependente desta associação e do movimento de nutrientes dentro da planta. De modo geral, a fase de rápido desenvolvimento do pimentão é acompanhada pelo aumento na absorção de nutrientes pela planta, que declina quando a taxa de crescimento diminui. Considerando que os adubos orgânicos, mais utilizados na produção de hortaliças, apresentam lenta liberação dos nutrientes para a solução do solo, torna-se necessária uma fonte mineral 
prontamente disponível, para garantir o desenvolvimento inicial dessas plantas.

O composto orgânico é um fertilizante orgânico produzido pela decomposição aeróbica de resíduos orgânicos de origem vegetal e animal, realizada por diferentes populações de microrganismos presentes nestes materiais. O produto final é um composto de qualidade, rico em nutrientes cuja utilização, além de melhorar as características físicas e químicas do solo, aumenta a CTC, proporcionando maior disponibilidade de nutrientes para plantas e microrganismos restaurando o ciclo biológico do solo (Sediyama et al., 2000).

Na região do Vale do Piranga, Zona da Mata mineira, existe grande disponibilidade de dejeto de suínos, que nas formas líquida ou sólida fermentadas podem ser utilizados na produção de composto orgânico para adubação de culturas, devido ao seu alto valor fertilizante (Vidigal et al., 1997; Sediyama et al., 2000). A prática da compostagem associada a um programa de produção de hortaliças pode proporcionar aumento da produtividade, pelo fornecimento de nutrientes e melhoria das características físicas e químicas do solo, além de reduzir a poluição ambiental, causada pelo lançamento dos dejetos de suínos nos cursos d'água. Neste sentido, objetivouse com este trabalho avaliar o efeito da adubação orgânica associada à adubação mineral na nutrição das plantas e produção de pimentão.

\section{MATERIAL E MÉTODOS}

O experimento foi conduzido na Fazenda Experimental Vale do Piranga, da EPAMIG, Oratórios (MG), à altitude média de $400 \mathrm{~m}$ e em Argissolo Vermelho-Amarelo, câmbico, fase terraço, com as características na camada de 0 a $20 \mathrm{~cm}: \mathrm{pH}\left(\mathrm{H}_{2} \mathrm{O} 1: 2,5\right)=5,7 ; \mathrm{MO}=26,5$ $\mathrm{g} \mathrm{kg}^{-1} ; \mathrm{P}=8,0 \mathrm{mg} \mathrm{dm}^{-3}$ e em cmol $\mathrm{dm}^{-3}$ : $\mathrm{K}^{+}=0,3 ; \mathrm{Ca}^{2+}=2,5 ; \mathrm{Mg}^{2+}=1,6 ; \mathrm{Al}^{3+}=0,0$ $\mathrm{e} \mathrm{H}^{+}+\mathrm{Al}^{3+}=3,24$.

O delineamento experimental foi de blocos casualizados, com quatro repetições, no esquema fatorial $4 \times 3$, quatro doses de adubo orgânico (0; 30; 60 e 90 t ha ${ }^{-1}$ de composto orgânico), calculadas com base no material fresco $(56 \%$ de umidade) e três doses de adubo mineral (0; 750 e $1500 \mathrm{~kg} \mathrm{ha}^{-1}$ da fórmula NPK 4-14-8, sendo iguais a $0 ; 50$ e $100 \%$ da adubação NPK recomendada para aplicação no sulco de plantio da cultura) (Ribeiro et al., 1999).

Cada parcela de $14 \mathrm{~m}^{2}$ constitui-se de 4 linhas de 3,5 $\mathrm{m}$ de comprimento, onde as 28 mudas foram distribuídas, no espaçamento de $1,0 \times 0,5 \mathrm{~m}$. Foram consideradas úteis as 10 plantas centrais de cada parcela.

O composto orgânico usado foi produzido com palha de café, bagaço de cana-de-açúcar e dejeto líquido de suínos na proporção, em volume, de $3,5: 7,0: 1,0$, respectivamente e relação $\mathrm{C} / \mathrm{N}$ inicial de 30:1, apresentando ao final do processo de compostagem as seguintes características: umidade a $65^{\circ} \mathrm{C}=56 \% ; \mathrm{pH}\left(\mathrm{H}_{2} \mathrm{O} 1: 2,5\right)=7,7$ e em $\mathrm{g} \mathrm{kg}^{-1}: \mathrm{N}$ - total $=27,2 ; \mathrm{P}=14,2 ; \mathrm{K}^{+}=$ 21,$3 ; \mathrm{Ca}^{2+}=14,2 ; \mathrm{Mg}^{2+}=3,3 ; \mathrm{S}=2,8$; $\mathrm{C}$ orgânico $=128,5$ e em mg kg-1 $: \mathrm{Fe}=$ 16,$7 ; \mathrm{Mn}=515 ; \mathrm{MO}=0,88 ; \mathrm{Zn}=141$; $\mathrm{Cu}=217 ; \mathrm{B}=27$ e a $\mathrm{CTC}=39,12 \mathrm{cmol}$ $\mathrm{kg}^{-1}$, analisados segundo metodologia da EMBRAPA (1999). O composto orgânico foi todo incorporado no sulco 15 dias antes do plantio e a adubação mineral foi aplicada nos sulcos de plantio, na época do transplante das mudas.

As mudas de pimentão, cultivar Magda, foram produzidas em copinhos de jornal, em casa de vegetação e foram transplantadas aos 45 dias após o semeio. A condução do experimento ocorreu no período compreendido entre os meses de maio a dezembro.

A irrigação foi feita por aspersão com turno de rega de dois dias, aplicando-se em média uma lâmina de água de $8 \mathrm{~mm}$, e as capinas, sempre que necessárias, foram feitas com enxada. $\mathrm{Na}$ prevenção de doenças fúngicas da parte aérea, foram efetuadas duas aplicações de calda bordaleza a $10 \%$.

O estado nutricional das plantas foi avaliado na época da floração, aproximadamente, 40 dias após o transplante das mudas e os resultados expressos em teor de nutrientes na matéria seca das folhas (Fontes, 2006). As folhas recém maduras coletadas em cada parcela foram secas em estufa com circulação de ar, à temperatura de $65-70^{\circ} \mathrm{C}$, por $72 \mathrm{~h}$. Posteriormente, as amostras foram moídas e analisadas quanto aos teores de N, $\mathrm{P}, \mathrm{K}, \mathrm{Ca}$ e $\mathrm{Mg}$, segundo procedimentos da EMBRAPA (1999).

A colheita dos frutos iniciou-se aos 70 dias após o transplante das mudas e foram avaliadas as características: produção de frutos total, comercial e não comercial. Os frutos comerciais foram classificados com base no comprimento e no diâmetro, em extra (frutos graúdos com 15-17 cm de comprimento e diâmetro igual ou superior a $7 \mathrm{~cm}$ ); especial (frutos médios com 12 a 15 cm de comprimento e diâmetro igual ou superior a $6 \mathrm{~cm}$ ) e primeira (frutos miúdos com 8 a $12 \mathrm{~cm}$ de comprimento e diâmetro igual ou superior a $4 \mathrm{~cm}$ ), segundo Correia (1984) e Ceagesp (2008), com pequenas modificações.

Os dados obtidos foram submetidos à análise de variância e de regressão, tendo como variáveis independentes as doses de adubo orgânico (AO) e de adubo mineral (AM), utilizando-se o "software" SAEG (2000). Os modelos foram escolhidos com base na significância dos coeficientes de regressão utilizando-se o teste " $\mathrm{t}$ " adotando-se o nível de até $5 \%$ de probabilidade.

\section{RESULTADOS E DISCUSSÃO}

Os teores foliares de N, K e Mg aumentaram com o aumento das doses de adubação orgânica e mineral. O menor teor de $\mathrm{N}$ (40,1 $\mathrm{g} \mathrm{kg}^{-1}$ ) foi estimado no tratamento sem adubação e o maior teor $\left(52,1 \mathrm{~g} \mathrm{~kg}^{-1}\right)$ foi estimado com a aplicação da maior dose de composto orgânico (90 t ha-1) associado à maior dose de adubação mineral, ou seja, $1500 \mathrm{~kg}$ da fórmula 4-14-8 (Figura 1A), valores acima do nível crítico (40,0 g $\mathrm{kg}^{-1}$ ) apresentado por Fontes (2006). A aplicação das doses de composto orgânico na ausência da adubação mineral estimou teores de $\mathrm{N}$ entre 40,1 e 44,3 $\mathrm{g} \mathrm{kg}^{-1}$, também acima do nível crítico, demonstrando que somente com a adubação orgânica as plantas estavam bem nutridas em N. A adição do adubo mineral ao orgânico proporcionou aumento nos teores foliares de $\mathrm{N}$ de até $30 \%$ em relação ao nível crítico sem, contudo 


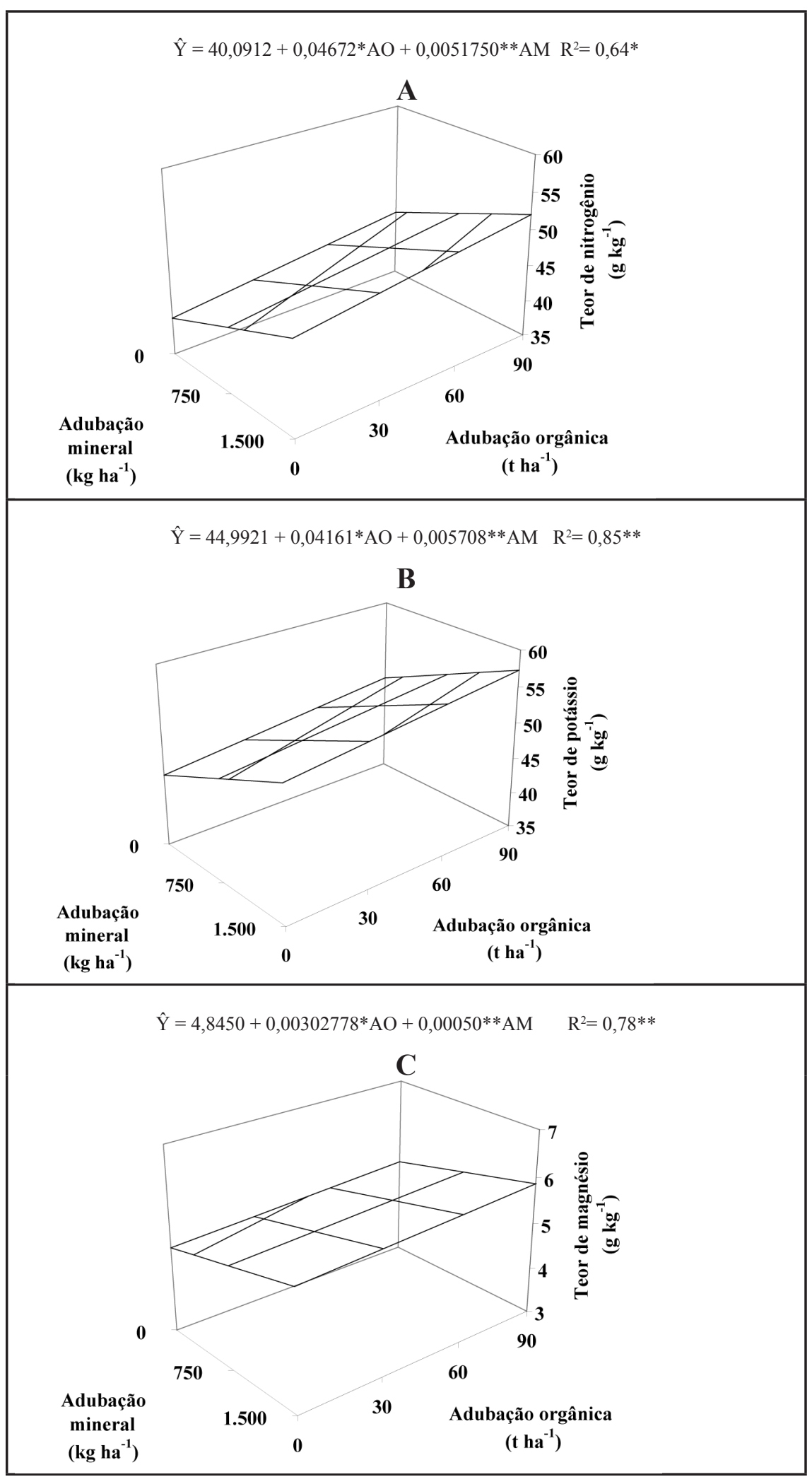

Figura 1. Teores de nutrientes em folhas de pimentão cv. Magda, no início da floração, em função de adubação orgânica (AO) e adubação mineral (AM), A) Nitrogênio, B) Potássio e C) Magnésio (nutrient content in leaves of pepper cv. Magda, at the beginning of flowering, as a function of the organic fertilization (OF) and mineral fertilization (CF), A) Nitrogen, B) Potássium and C) Magnesium). Oratórios, EPAMIG, 2003. causar toxidez.

Os teores foliares de $\mathrm{K}$ variaram de 44,9 a 57,3 $\mathrm{g} \mathrm{kg}^{-1}$ (Figura 1B), sendo o maior teor estimado com a aplicação da maior dose de composto orgânico associada à maior dose de adubo mineral. As doses de composto orgânico, na ausência da adubação mineral, estimaram teores foliares de $\mathrm{K}$ que variaram de 45,0 a 48,7 $\mathrm{g} \mathrm{kg}^{-1}$. Quando se associou as doses de composto com as de adubo mineral, os teores de $\mathrm{K}$ foram superiores, variando de 49,3 a 57,3 $\mathrm{g} \mathrm{kg}^{-1}$. Os teores de $\mathrm{K}$ estiveram dentro e acima da faixa adequada para pimentão (35,0-45,0 g $\mathrm{kg}^{-1}$ ), conforme Jones Jr. et al. (1991) e abaixo do nível crítico de $58,0 \mathrm{~g} \mathrm{~kg}^{-1}$ apresentado por Fontes (2006).

Teores foliares de $\mathrm{Mg}$ variaram de 4,8-5,9 $\mathrm{g} \mathrm{kg}^{-1}$, sendo o maior valor estimado com a aplicação da maior dose de composto orgânico associada à maior dose de adubo mineral (Figura 1C). O menor teor foi estimado no tratamento sem adubação. Todos os teores foliares de $\mathrm{Mg}$ estiveram dentro da faixa adequada para o pimentão (3,0-10,0 $\left.\mathrm{g} \mathrm{kg}^{-1}\right)$, conforme Jones Jr. et al. (1991).

$\mathrm{O}$ teor foliar de $\mathrm{P}$ apresentou pequena variação, sendo observados valores entre 3,5-4,4 $\mathrm{g} \mathrm{kg}^{-1}$. Embora os efeitos de adubação nos teores foliares de $\mathrm{P}$ tenham sido significativos, não houve ajuste de curva de resposta, sendo o teor médio estimado igual a $3,9 \mathrm{~g} \mathrm{~kg}^{-1}$. Os teores foliar estiveram dentro da faixa adequada para o pimentão que é de 2,0-7,0 $\mathrm{g} \mathrm{kg}^{-1}$ (Jones Jr. et al., 1991), mas inferiores ao nível crítico de $5,5 \mathrm{~g}$ $\mathrm{kg}^{-1}$ apresentado por Fontes (2006), sem prejuízo à produção de frutos.

Embora os efeitos de adubação nos teores foliares de $\mathrm{Ca}$ tenham sido significativos, não houve ajuste de curva de resposta. Os teores de $\mathrm{Ca}$ encontrados nas folhas de pimentão situaram-se entre 13,8-17,3 $\mathrm{g} \mathrm{kg}^{-1}$, sendo o valor médio estimado igual a 15,4 $\mathrm{g} \mathrm{ha}^{-1}$, que está dentro da faixa adequada para o pimentão (13,0-28,0 $\left.\mathrm{g} \mathrm{kg}^{-1}\right)$, conforme Jones Jr. et al. (1991) e próximo ao nível crítico apresentado por Fontes (2006). Outros autores trabalhando com a cultura do pimentão encontraram valores de $\mathrm{Ca}$ superiores ao observado neste estudo. Segundo Ribeiro (2000) o limite mínimo para o Ca nas folhas é de $24,3 \mathrm{~g} \mathrm{~kg}^{-1}$. 
Marcussi (2005), avaliando os teores de macronutrientes em folhas de pimentão, até 140 dias após o transplante, observou teor médio de cálcio de $20,5 \mathrm{~g} \mathrm{~kg}^{-1}$ aos 40 dias.

Alguns autores encontraram nas folhas de pimentão, também coletadas no início da floração, teores, em $\mathrm{g} \mathrm{kg}^{-1}$, variando de: $30-60$; 2-8 e 25-60 respectivamente, para N, P e K (Melo et al., 2000; Ribeiro et al., 2000; Oliveira et al., 2004; Marcussi, 2005). Desta forma, os teores foliares de N, P e K obtidos neste trabalho encontram-se dentro das faixas observadas por esses autores. Para teores foliares de P e K, os valores encontrados ficaram abaixo do nível crítico citado por Fontes (2006), no entanto a produção comercial não foi reduzida.

Quanto à produção de frutos, os resultados apresentados nas Figuras 2 e 3 ressaltam a importância do composto orgânico e o efeito aditivo da adubação mineral no incremento da produtividade do pimentão.

O número total de frutos (comercial + refugo) aumentou até a maior dose aplicada de composto orgânico (90 t $\mathrm{ha}^{-1}$ ) associada à maior dose de adubação mineral, ou seja, $1500 \mathrm{~kg} \mathrm{ha}^{-1} \mathrm{de}$ 4-14-8 (Figura 2A). O número máximo de frutos comerciais foi estimado com a aplicação de 84,03 tha ${ }^{-1}$ de composto or- gânico também associado à maior dose de adubação mineral (Figura 2B).

As produtividades máximas de frutos total $\left(65,96 \mathrm{t} \mathrm{ha}^{-1}\right)$, comercial $(60,41$ $\left.\mathrm{t} \mathrm{ha}^{-1}\right)$ e das classes extra $\left(27,86 \mathrm{t} \mathrm{ha}^{-1}\right)$, especial $\left(20,72 \mathrm{t} \mathrm{ha}^{-1}\right)$ e primeira $(12,09$ $\mathrm{t} \mathrm{ha}^{-1}$ ) foram estimadas com a aplicação de 88,18; 84,43; 90,00; 87,13 e 67,69 t ha $^{-1}$ de composto orgânico, respectivamente, quando associada à maior dose de adubo mineral (Figuras 3A, 3B, 3C, 3D e 3E). Com aplicação de 84,43 $\mathrm{t} \mathrm{ha}^{-1}$ de composto orgânico associado a 750 $\mathrm{kg} \mathrm{ha}^{-1}$ da fórmula 4-14-8, a produção estimada foi de 54,37 $\mathrm{t} \mathrm{ha}^{-1}$ de frutos comerciais, demonstrando a possibilidade de economizar 50\% na adubação mineral recomendada, com redução de apenas $10 \%$ na produtividade de frutos comerciais. Peixoto et al. (1999), avaliando o desempenho agronômico de genótipos de pimentão em Araguari (MG), obtiveram produtividade inferior à observada neste estudo $\left(34,60 \mathrm{t} \mathrm{ha}^{-1}\right)$, para a mesma cultivar Magda.

$\mathrm{Na}$ ausência da adubação mineral a produção comercial variou de 16,35 a 51,21 $\mathrm{t} \mathrm{ha}^{-1}$, sendo a máxima estimada com a aplicação de 84,43 tha-1 de composto orgânico. Por outro lado, quando não usou adubação orgânica, a produção comercial estimada com a maior dose do adubo mineral foi $25,84 \mathrm{t} \mathrm{ha}^{-1}$, ou seja, 49,53\% menor. No entanto, a bai- xa produção obtida apenas com adubo mineral, pode ser atribuída à ausência das adubações de cobertura, pois, neste experimento, utilizou-se apenas a adubação de plantio.

De acordo com Serrano Cermeño (1990) citado por Lúcio et al. (2003) a produtividade do pimentão em campo aberto está entre 40-60 t ha-1. Os ganhos obtidos, especialmente na produção de frutos total e comercial ressaltam a importância da utilização de adubo orgânico no aumento da produtividade de pimentão, uma vez que a adubação mineral foi responsável por um acréscimo de apenas 9,95 e 9,21 $\mathrm{t} \mathrm{ha}^{-1} \mathrm{de}$ frutos, representando 15,08 e 15,24\% da produção máxima, respectivamente (Figuras 3A e 3B).

Segundo Ribeiro et al. (2000) a aplicação de adubo orgânico (vermicomposto ou esterco de curral) na ausência do adubo mineral proporcionou ganho adicional de 3,5 tha-1 em relação à testemunha, enquanto na presença de adubo mineral este ganho adicional foi de 7,0 $\mathrm{t}^{\mathrm{a}} \mathrm{a}^{-1}$. Por outro lado Roe et al. (1997) e Mello et al. (2000) não observaram aumento na produção comercial e total de frutos de pimentão, respectivamente, com a aplicação de composto orgânico e $100 \%$ do nível de aplicação de fertilizante NPK em relação ao uso do fertilizante mineral somente.

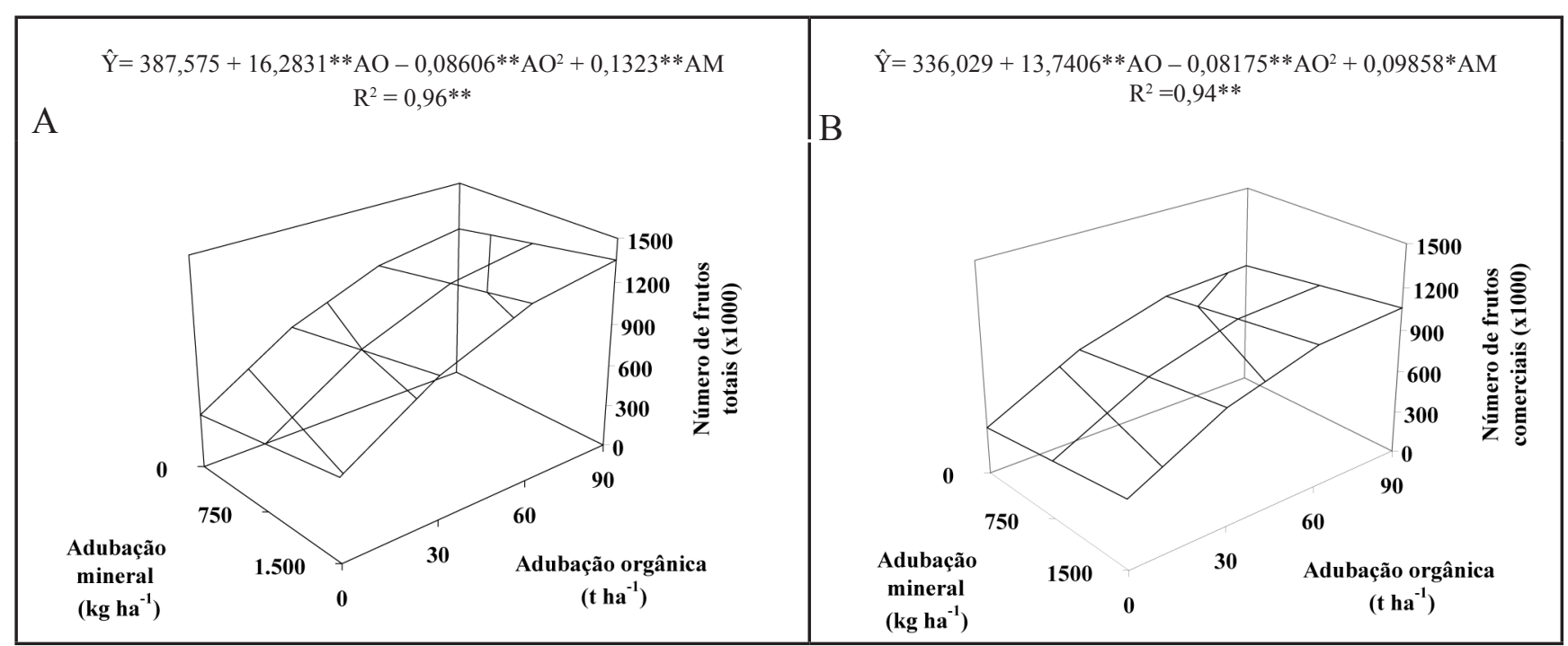

Figura 2. Número de frutos por hectare (x 1000), A) frutos totais e B) frutos comerciais, de pimentão, cv. Magda, em função de adubação orgânica (AO) e adubação mineral (AM) (number of fruits (x 1000), A) total fruits and B) commercial fruits, of pepper cv. Magda, as a function of organic fertilization (OF) and mineral fertilizer (CF)). Oratórios, EPAMIG, 2003. 


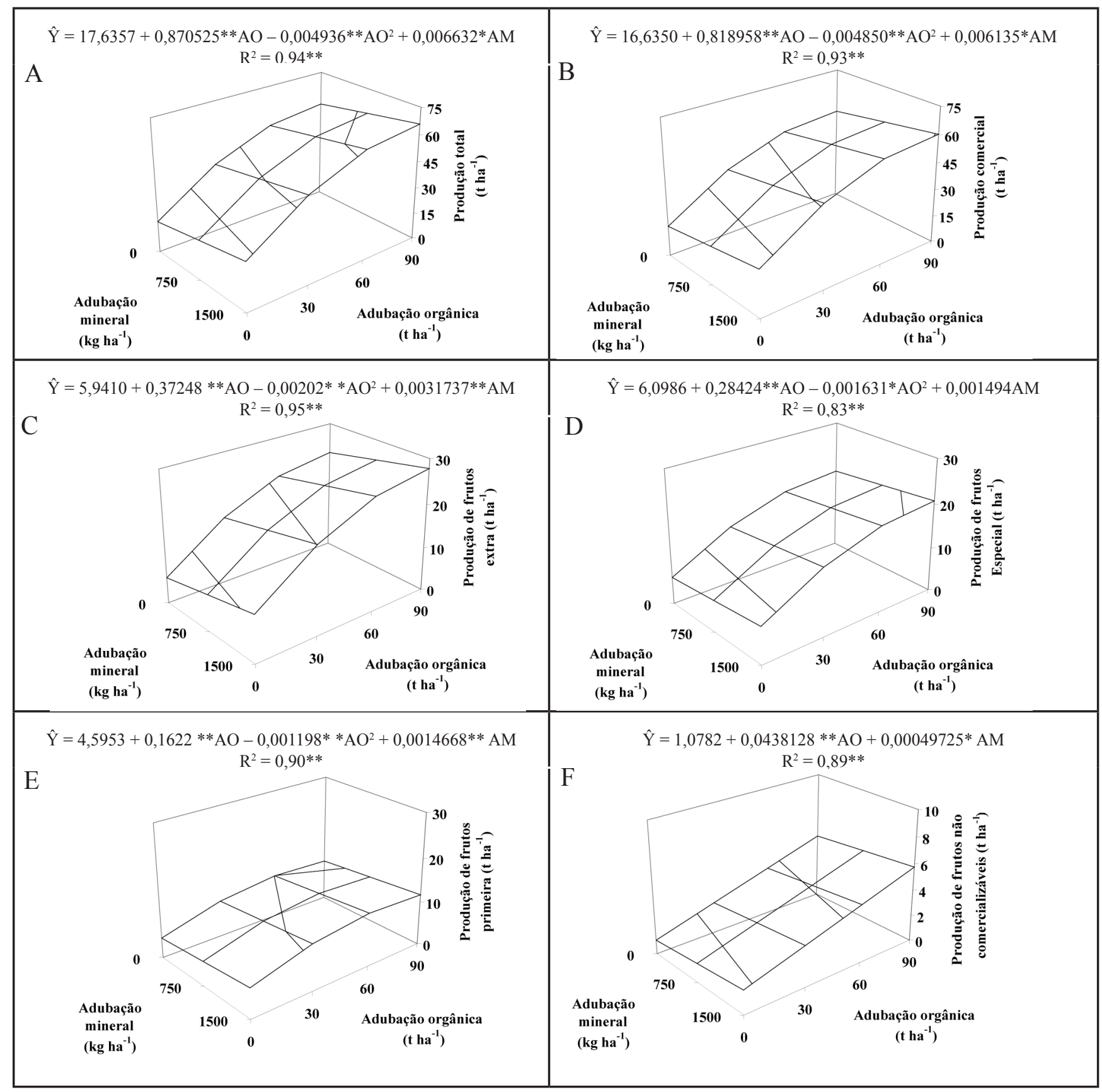

Figura 3. Produção de frutos de pimentão, cv. Magda, em função de adubação orgânica (AO) e adubação mineral (AM). A) produção total de frutos, B) produção de frutos comercial, C) frutos da classe extra, D) frutos da classe especial, E) frutos da classe primeira e F) frutos não comerciais (pepper fruit production, cv. Magda, as a function of organic fertilization (OF) and mineral fertilizer (CF). A) total production of fruits, B) production of fruits commercial, C) fruits of the extra class, D) fruits of the special class, E) fruits of the first class and F) fruits don’t commercial). Oratórios, EPAMIG, 2003.

A aplicação de $84,43 \mathrm{t} \mathrm{ha}^{-1}$ de composto orgânico combinada com a maior dose de adubo mineral estimou a produção comercial máxima e proporcionou plantas com teores foliares de N, P, K, Ca e Mg iguais a 51,8; 3,9; 57,$1 ; 15,4$ e $5,8 \mathrm{~g} \mathrm{~kg}^{-1}$, respectivamente. Com base nesta produção pode-se inferir que as plantas estavam com bom estado nutricional, apesar de alguns nutrientes estarem abaixo do nível crítico encontrado na literatura.

Considerando que o nível crítico dos teores foliares de nutrientes é aquele correspondente a $95 \%$ da produção comercial máxima (Fontes, 2006), que neste trabalho foi igual a $57,39 \mathrm{t} \mathrm{ha}^{-1}$ estimada com a aplicação de $84,43 \mathrm{t}$ ha ${ }^{-1}$ de composto associada a $1008 \mathrm{~kg}$ ha $^{-1}$ da fórmula 4-14-8, os níveis críticos obtidos para esta condição seriam, em g $\mathrm{kg}^{-1}: 49,2 ; 3,9 ; 54,3 ; 15,4$ e 5,6 para $\mathrm{N}$, $\mathrm{P}, \mathrm{K}, \mathrm{Ca}$ e $\mathrm{Mg}$, respectivamente.

A aplicação de composto orgânico 
parece ter atendido às exigências nutricionais do pimentão, provavelmente, em função do fornecimento equilibrado de macro e micronutrientes e a liberação desses durante o ciclo da cultura, além de melhoria na estruturação do solo. Por outro lado, o efeito aditivo da adubação mineral pode ser atribuído ao fato deste possuir nutrientes mais prontamente absorvíveis pelas plantas, o que favorece o crescimento, principalmente, na fase inicial do ciclo.

As produtividades de frutos total, comercial e das classes extra, especial e primeira (Figuras 3A, 3B, 3C, 3D e 3E) também apresentaram maiores ganhos com adição de composto orgânico. As contribuições das classes extra, especial e primeira na produção máxima de frutos comerciais foram respectivamente: 45,93\%, 34,29\% e 19,78\% para a aplicação de 84,43 tha he $^{-1}$ de adubo orgânico associado a $1.500 \mathrm{~kg} \mathrm{ha}^{-1}$ da fórmula 4-14-8. Isto significa que quando as plantas estiveram bem nutridas a sua contribuição foi maior na produção de frutos extra, de maior valor comercial, e menor contribuição na produção de frutos da classe primeira.

A maior produção de frutos não comerciais $\left(5,52 \mathrm{t} \mathrm{ha}^{-1}\right)$ foi estimada com a aplicação da maior dose de composto orgânico associado à maior dose de adubação mineral (Figura 3F). O fato de se obter maior produção de frutos não comerciais nas maiores doses de composto orgânico deve-se, provavelmente, à alta produção total de frutos em conseqüência da maior disponibilidade de nutrientes, proporcionando melhor crescimento e desenvolvimento das plantas nestes tratamentos. Plantas com maior número de ramos produzem maior número de frutos, porém alguns menores, que não entram no padrão de comercialização. Negreiros (1995) verificou que plantas de pimentão com maior número de ramos produziram maior número de frutos de menor peso médio.

Verificou-se maior número de frutos podres nas últimas colheitas, especialmente, no tratamento com maior dose de composto orgânico $90 \mathrm{t} \mathrm{ha}^{-1}$. Esses dados não foram apresentados separadamente, mas somadas à produção de frutos não comerciais. De modo geral, a podridão de frutos surgiu após ataque inicial de insetos e, posteriormente, penetração de agentes patogênicos. As perdas devidas ao apodrecimento e mesmo à maior produção de frutos não comercializáveis, nas maiores doses de composto orgânico, não influenciaram a produção comercial e por classes de frutos, uma vez que estas características se destacaram nestas doses.

O composto orgânico produzido com palha de café, bagaço de canade-açúcar e dejeto líquido de suínos foi eficiente na nutrição das plantas de pimentão e consequentemente no aumento na produtividade de frutos. A adubação mineral NPK apresentou efeito aditivo na produção de frutos. A classe extra foi responsável pela maior parte da produção de frutos comerciais. Para as condições do trabalho, a máxima produtividade de frutos comerciais foi estimada quando se associou 84,43 $\mathrm{tha}^{-1}$ de composto orgânico com $1500 \mathrm{~kg} \mathrm{ha}^{-1}$ da fórmula 4-14-8, aplicado nos sulcos de plantio.

\section{AGRADECIMENTOS}

À FAPEMIG pelo auxílio financeiro ao projeto e pelas bolsas BIPDT.

\section{REFERÊNCIAS}

CEAGESP. 2008. Norma de classificação do pimentão para o programa brasileiro para a melhoria dos padrões comerciais e embalagens de hortigranjeiros. Disponível em www.ceasacampinas.com.br/servicos/ padronizacao/imagens/pimentao_norma.pdf Acesso em 30 de outubro de 2008.

CORREIA LG. 1984. Colheita, rendimento, classificação de pimentão e pimenta. Informe agropecuário, Belo Horizonte: EPAMIG 10: 70-72.

EMBRAPA. 1999. Manual de análises químicas de solos, plantas e fertilizantes. Brasília: Embrapa Comunicação para Transferência de Tecnologia, 370p.

FILGUEIRA FAR. 2000. Manual de olericultura: Agrotecnologia moderna na produção e comercialização de hortaliças. Viçosa: UFV, $402 p$.

FONTES PCR. 2006. Diagnóstico do estado nutricional das plantas. Viçosa: UFV, 122p.

GALVÃO JCC; MIRANDA GV; SANTOS IC. 1999. Adubação orgânica. Revista Cultivar 2: 38-41.

JONES JR. JB; WOLF B; MILLS HA. 1991. Plant analysis handbook: a practical sampling, preparation, analysis and interpretation guide.
Athens: Micro-Macro, 213p.

LÚCIO AD; SOUZA MF; HELDWEIN AB; LIEBERKNECHT D; CARPES RH; CARVALHO MP. 2003. Tamanho da amostra e método de amostragem para avaliação de características do pimentão em estufa plástica. Horticultura Brasileira 21: 181-185.

MARCUSSI FFN. 2005. Uso da fertirrigação e teores de macronutrientes em plantas de pimentão. Engenharia Agrícola 25: 642-650.

MELO SC; PEREIRA HS; VITTI GC. 2000. Efeito de fertilizantes orgânicos na nutrição e produção do pimentão. Horticultura Brasileira 18: 200-203.

NEGREIROS MZ. 1995. Crescimento, partição de matéria seca, produção e acúmulo de macronutrientes de plantas de pimentão (Capsicum annuum L.) em cultivo podado e com cobertura morta. Viçosa: UFV. 187p. (Tese doutorado).

OLIVEIRA AP; PAES RA; SOUZA AP; DORNELAS CSM; SILVARA. 2004. Produção de pimentão em função da concentração de urina de vaca aplicada via foliar e da adubação com NPK. Agropecuária Técnica 25: 37-43.

PEIXOTO JR; RAMOS RS; FARIA JUNIOR B; SILVA CM; ANGELIS B. 1999. Avaliação de genótipos de pimentão no período de inverno, em Araguari, MG. Pesquisa Agropecuária Brasileira 34: 1865-1869.

RIBEIRO AC; GUIMARÃES PTG; ALVAREZ VVH. 1999. Comissão de Fertilidade do Solo do Estado de Minas Gerais. Recomendações para o uso de corretivos e fertilizantes em Minas Gerais - $5^{a}$ aproximação. Viçosa, MG. $359 \mathrm{p}$.

RIBEIRO GL; LOPES JC; MARTINS FILHO S; RAMALHO SS. 2000. Adubação orgânica na produção do pimentão. Horticultura Brasileira 18: 134-137.

RODRIGUES ET; CASALI VWD. 1999. Rendimento e concentração de nutrientes em alface, em função das adubações orgânica e mineral. Horticultura Brasileira 17: 125128.

ROE NE; STOFFELLA PJ; GRAETZ D. 1997. Composts from various municipal solid waste feedstocks affect vegetable crops. II. Growth, yields, and fruit quality. Journal American Society Horticultural Science 122: 433-437.

SAEG. Sistema para Análise Estatística. 2000. Versão 8,0. Viçosa-MG: Fundação Artur Bernardes.

SCHERER, EE. 1998. Utilização de estercos suínos como fonte de nitrogênio: bases para a adubação dos sistemas milho/feijão e feijão/milho, em cultivo de sucessão. Florianópolis:EPAGRI. 49p (Boletim Técnico, 99).

SEDIYAMA MAN; GARCIA NCP; VIDIGAL SM; MATOS AT. 2000. Nutrientes em compostos orgânicos de resíduos vegetais e dejetos de suínos. Scientia Agricola 57: 185-189.

VIDIGAL SM; SEDIYAMA MAN; GARCIA NCP; MATOS AT. 1997. Produção de alface cultivada com diferentes compostos orgânicos e dejetos de suínos. Horticultura Brasileira 15: 35-39. 